\title{
Periscope
}

The sensations from puncture of a vein are usually those of dermal puncture alone and the vessel puncture gives no sensation. Occasionally a small nerve may be affected, but the sensations, although similar to those of arterial puncture, are much less severe.

Punctures made with a needle at right angles to the surface of the skin are accompanied by a simple pricking sensation of an acute type which subsides at once and is accompanied by a slight local inflammatory reaction. If the needle be introduced tangentially the pain is more irritating but not nauseating, and there is a definite relationship between the severity of the pain and the degree of inflammation. A needle can usually be moved back and forward in the subcutaneous fat with little or no pain, and no unpleasant reflex effect or inflammation. Once the needle is within the muscles, sensations are as a rule absent.

As soon as the deep fascia is reached, sensations similar to those described in relation to arterial puncture are found. They are most marked from the outer aspect of the fascia, and subside once the fascia is punctured. If tension be exerted by the needle on the deep fascia, sensations may continue and may even cause the subject to faint. This may be due to a plexus of arterial vessels just superficial to the fascia, or to a nervous network. The more marked sensations of the smaller vessels may be dependent on their richer nerve supply.

The pain from puncture of deep fascial planes and of small arteries resembles that found in certain forms of neuralgia.

H. C. Bazett and B. M'Glone (Brain, r 928, li., I8-23).

\section{THE SYMPTOMATOLOGY OF TUMOURS OF THE TEMPORAL LOBE.}

The temporo-sphenoidal lobe is too large an area of the brain for lesions, variable in type and extent, to produce any one definite train of symptoms and signs. There is thus no definite temporal lobe syndrome.

The author here analyses the various symptoms and signs in their order of frequency found in thirty-eight tumours of this lobe.

Headache was present in every case. There may be local pain or tenderness, and this may be characteristic, coming on suddenly in sharp agonising paroxysms and disappearing abruptly. It is probably due to local pressure on the trigeminal nerve. Vomiting occurred in 50 per cent. of the cases, and incontinence in 20 per cent.; they are merely a symptom of increased intracranial pressure, and have no localising value. Papillœedema was found in 86 per cent. of cases. In the incipient stages the comparative degree of swelling of the two 


\section{Periscope}

nerve heads on the two sides may be of lateralising value. Defects of memory were present in $5^{\circ}$ per cent., usually both for recent and past events, as contrasted with memory changes in frontal lobe tumours which are confined to recent events. The tendency to attribute psychic disturbances to lesions of the left hemisphere in right-handed people is not supported by clinical facts. Fits occurred in 50 per cent., and were of localising value in 40 per cent. They were a relatively early symptom, especially focal sensory fits. Motor and sensory disturbances are obviously a neighbourhood symptom, and were observed in 92 per cent. The most common was a contralateral lower facial weakness (66 per cent.). The plantar response had a lateralising value in about 45 per cent. of the cases, and is a later sign than the loss of the abdominal reflex. The so-called "pseudo-cerebellar signs" are of no value. Defects of the visual fields are relatively rare. Disturbances of hearing are of no lateralising value, but increased impairment of hearing in both ears in a case of intracranial tumour suggests a temporal lesion. Disturbances of smell and taste are of no value. Aphasia is not of as great diagnostic importance as is usually believed. It was here present in only $\mathbf{2} 2$ of $2 \mathrm{I}$ right-handed cases, and was the first localising sign in only 4 . Oculo-pupillary changes were observed in $2 \mathrm{I}$ cases. They are transitory and recur from time to time, but later became permanent. The commonest is the size of the pupil. Complete oculomotor paralysis is not seen.

Anatole Kolodny (Brain, 1928, li., 385-41 7).

A. N. B.

\section{POST-HERNIAL FIBROUS STRICTURE OF THE SMALL INTESTINE.}

After describing the case of a female, aged 55 years, the occurrence of occlusion of the small intestine by fibrosis, following a right femoral hernia which had been operated on for the relief of strangulation thirteen months previously, Matry adds that fibrous strictures of the small intestine are well known. They may follow a mere contusion of the bowel but probably the most common origin is a hernial strangulation. Necrosis of the mucosa and troubles resulting from compression of the mesenteric blood vessels play their part in the production of fibrous stenosis of the small intestine. The stenosis becomes gradually established long after the herniotomy has apparently been successfully accomplished.

Matry, "Occlusion de l'intestine grêle par sténose fibreuse Suite d'un étranglement herniaire" (Bull. et mém. de la soc. nat. de chirurg., Paris, I919, lv., 23). 